\section{Fasciola gigantica in the Common Bile Duct: Diagnosis by ERCP}

A 40-year-old German woman traveled in Madagascar in June 1992. In September 1992, she presented with a hepatic abscess, leading to a right hemihepatectomy. The histology proved an abscess, with involvement of the bile ducts and tissue eosinophilia, suggesting helminthic infection. The culture was sterile.

She was readmitted in June 1993 when a new abscess occurred. The physical examination was normal after hemihepatectomy. There was no blood eosinophilia, leukocyte alkaline phosphatase (LAP) was $69 \mathrm{U} / 1$ (n 11-33), and alanine aminotransferase (ALT) was $21 \mathrm{U} / 1$ (n 5-19). A high concentration of antibodies against Fasciola hepatica was detected $(50 \mathrm{U}, \mathrm{n}<10$; ELISA) and a low concentration of antibodies against Ascaris (1:20, $\mathrm{n}<1: 20 ;$ IHA). No parasites or worm eggs were detected in the bile or stool after enrichment.

Endoscopic retrograde cholangiography showed irregularities of the distal common bile duct, compatible with chronic cholangitis and a variable, longish foreign body in the prepapillary region (Figure 1). After papillotomy, a live adult Fasciola gigantica, $3.9 \mathrm{~cm}$ in length, (identification by D. Büttner, Bernhard-Nocht-Institut, Hamburg) was extracted (Figure 2) using the Dormia basket. Systemic treatment with praziquantel was given for seven days $(3 \times 25 \mathrm{mg} / \mathrm{kg}$ b.w.). A follow-up examination after 17 months showed no signs of a new abscess.

Fascioliasis is a rare cause of focal liver lesions (1). It should be suspected if a sterile liver abscess is found with cholangitis and tissue eosinophilia. Immunoassays are helpful in the differential diagnosis, but may be hampered by nonspecific cross reactions with other helminths (2). Specific parasitologic diagnosis in Fasciola infection can be difficult, as the number of worm eggs in stool or bile is often low, even after enrichment before microscopy. In these cases, endoscopic retrograde cholangiopancreatography appears to be a favorable diagnostic and therapeutic procedure, if a parasitic origin of cholangitis (3) or even pancreatitis (4) is suspected, reducing the need for surgery (5). However, systemic anthelminthic treatment should follow, since the presence of further worms cannot be excluded.

\section{References}

1. Bechtel U, Feucht H, Held E, Vogl T, Nothdurft H. Fasciola hepatica: Infektion einer Familie. Dtsch Med Wochenschr 1992; 117: 978-82.

2. Abdulfattah M, Yousef S, Nasr M, Fouad A, Abdulwahab S. Indirect fluorescent antibody test in diagnosis of acute fasciolitic syndrome. J Egypt Soc Parasitol 1992; 22; $261-4$.

3. Veerappan A, Siegel J, Podany J, Prudente R, Gelb A. Fasciola hepatica pancreatitis: endoscopic extraction of live parasites. Gastrointest Endose 1991; 37: 473-5.

4. Saraswat V, Gupta R, Dhiman R, Gujral R. Biliary ascariasis: endoscopic extraction of a living worm from the bile duct. Endoscopy 1993; 25: 552-3.

5. Carrero P, González-Pastrana M, Garcia-Carbajosa S, Manzanares J. Hallazgo parasitologico durante la cirugia exploratoria de la via biliar. Enferm Infecc Microbiol Clin 1992: 10: 497-8.

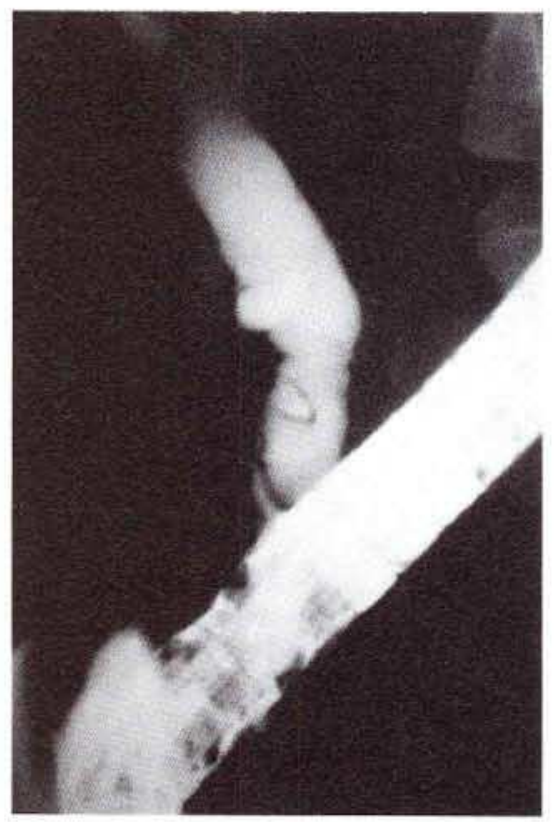

Figure 1: Cholangiography, showing an irregular common bile duct with a longish, mobile foreign body

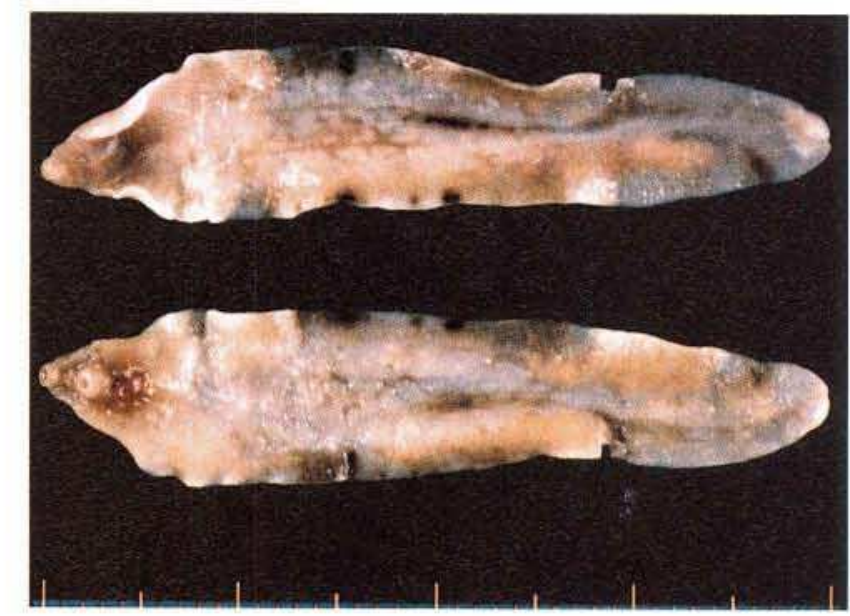

Figure 2: Extracted adult Fasciola gigantica, with still visible impressions from the Dormia basket.

H. Schwacha', M. Keuchel', G. Gagesch'2, F. Hagenmüller' 'First Dept. of Medicine, Altona General Hospital, Hamburg, Germany

${ }^{2}$ Clinical Dept., Bernhard Nocht Institute for Tropical Medicine, Hamburg, Germany

\section{Corresponding Author}

F. Hagenmüller, M.D.

1. Medizinische Abteilung

Allgemeines Krankenhaus Altona

Paul-Ehrlich-Strasse 1

22763 Hamburg

Germany

Fax: $+49-40-88224902$ 